\title{
The Role of Teachers' Beliefs in the Language Teaching-learning Process
}

\author{
$\mathrm{Li} \mathrm{Xu}$ \\ The School of Foreign Languages, Dalian University of Technology, Dalian City, Liaoning Province, China \\ Email: margaretx2007@hotmail.com
}

\begin{abstract}
Teachers' beliefs are important for understanding and improving educational process. They closely guide language teachers to adopt their teaching strategies for coping with their daily language teaching challenges, influence their general well-being, and in turn, shape language learners' learning environment, their motivation and their language achievement and ability. This essay studies some previous researches on teachers' beliefs, and analyzes the role of three teachers' beliefs in the language teaching-learning process. The first part clarifies the concept of teachers' beliefs, the second part illustrates three essential teachers' beliefs about learners, learning and teachers themselves, and their role in the language teaching-learning process, the third part is the conclusion, which is consistent with the concept of teachers' beliefs.
\end{abstract}

Index Terms - teachers' beliefs, the language teaching-learning, learners, teachers

"Teachers as reflective practitioners, if they want to be effective in whatever approach they decide to take, are expected to act consistently in accordance with their expressed beliefs. Unfortunately, ...there is almost always a discrepancy between what professionals say they believe and the way they act. In teaching, if the discrepancy... is a large one, then learners are likely to receive confused and confusing messages. " (Marion Williams et al., 1997)

In an effort to improve teachers' self-awareness in this respect, some educational theorists have fostered the notion of critical reflection. The intention is to enable teachers to become reflective practitioners and to stress that teachers should be aware of their belief systems and constantly monitor how much their actions reflect those beliefs or are in keeping with them. Thus these educational theorists consider the teachers' beliefs to be of critical importance.

\section{TEACHERS’ BELIEFS AND THE THEORETICAL SOURCES}

There is growing evidence to indicate that teachers are highly influenced by their beliefs, which in turn are closely linked to their values, to their views of the world, and to their understanding of their place within it.

Then what does teachers' beliefs mean? Firstly we need to make clear of the basic concept: belief. Michael Borg's (2001) defined that "a belief is a proposition which may be consciously or unconsciously held, is evaluative in that it is accepted as true by the individual, and is therefore imbued with emotive commitment; further, it serves as a guide to thought and behavior." Most definitions of belief propose that beliefs dispose or guide people's thinking and action.

Beliefs play an important role in many aspects of teaching, as well as in life. They are involved in helping individuals make sense of the world, influencing how new information is perceived, and whether it is accepted or rejected. Beliefs color memories with their evaluation and judgment, and serve to frame our understanding of events.

Further, we come to consider teachers' beliefs, which are difficult to define and evaluate, and have not been notoriously defined, but we can find a number of statements to help us understand.

The British educational theorist Pajares (1992) noted that teachers' beliefs have a greater influence than the teachers' knowledge on the way they plan their lessons, on the kinds of decisions they make, and on their general classroom practice. Teachers' beliefs are central to determining their actual behavior towards students. If teachers can identify the level of students' capabilities, they will try to select and adjust their behavior and instructional choice accordingly.

Social constructionists also found that teacher's beliefs were "far more influential than knowledge in determining how individuals organize and define tasks and problems, and were better predictors of how teachers behave in the classroom. They tend to be culturally bound, to be formed early in life and to be resistant to change." (Marion Williams et al., 1997) They are closely related to what we think, we know, but provide an affective filter which screens, redefines, distorts, or reshapes subsequent thinking and information processing (Nespor 1987).

Kennedy (1997) attributed that it is not clear what the source of those beliefs might be - a product of their upbringing, a reflection of their life experiences, or a result of socialization processes in schools. Nevertheless, teachers and teacher candidates have strong beliefs about the role that education can play, about explanations for individual variation in academic performance, about right and wrong in a classroom, and many other areas. Kennedy asserts that these beliefs are used to evaluate the new ideas about teaching that teachers and teacher candidates confront in their methods classes. Those teachings that square with their beliefs are recognized and characterized as "what's new?" Teachings that challenge their beliefs are dismissed as theoretical, unworkable, or even simply wrong.

One Chinese scholar Zhou Guotao (1997) says that a teacher's beliefs are formed during the teaching process and reflect the teacher's subjective knowledge of relevant educational phenomenon, especially towards his/her own teaching 
ability and his or her students.

The Chinese educationist Xin Tao (1999) finds that the sources of teacher beliefs, as the result of self-construction and cultural interaction, are the result of social history and culture.

By reading relevant books and articles, the author form a thinking frame that constructivism psychologists claim a teacher's beliefs as the result of his or her self-construction. The beliefs arise from the teacher's own direct experience. Each teacher has different processes of self-construction. And social psychologists emphasize the importance of social cultural impact on a teacher's beliefs. They think that these beliefs are formed in the course of accepting culture. The cultural transmission depends on three factors: enculturation, education and schooling.

Therefore, in our opinion, a teacher's beliefs are more influential than a teacher's knowledge on determining his or her teaching activities. They result from the teacher's self-instruction, which is accumulated from social history and culture, personal experience and education, the teacher's teaching ability and students, etc.

Heather Davis and Carey Andrzejewski (2009) asserted that beliefs essentially function in a way similar to a lens on a magnifying glass. They clarify and guide interpretation of what may be ambiguous or unfocused. Generally, teachers interpret ambiguous situations in ways that are consistent with their beliefs. Beliefs also serve as a foundation for setting goals and standards by framing what is viewed in detail and focusing teachers' attention and energy. Similarly, they delimit what is peripheral, determining what teachers do not see, emphasize, or examine. Because beliefs help teachers to make sense of what they experience in the classroom, they create meaning for teachers. Moreover, they prepare teachers to experience certain emotions by mapping pleasant feelings onto some experiences (i.e., success or failure) and unpleasant feelings onto others.

Debate continues about the extent to which teachers' beliefs and their identity as teachers are the same. The literature on teachers' beliefs suggests teachers may simultaneously hold beliefs that are inconsistent, in conflict, and even contradictory and still see themselves as a teacher. Fred Korthagen (2004) posits teachers are likely to be the most effective when their beliefs are aligned with each other and with the field.

The focus research areas are "teachers' beliefs about teaching, learning, and learners; subject matter; self as a teacher, or the role of a teacher." (Michael 2001) Here we are going to study three of them which we think are essential.

\section{ThreE Types of Teachers’ Beliefs And Their Significant Roles In the LANGUage TeaChing-LEARNing PROCESS}

\section{A. Beliefs about Learners}

Teachers may hold any one or a combination of beliefs about those whom they teach. The sociologist Roland Meighan (1990) has suggested that learners may be construed metaphorically as:

- resisters

- receptacles

- raw material

- clients

- partners

. individual explorers

- democratic explorers

Such constructions reflect individual teacher's views of the world and also have a profound influence on their classroom practice. The first three constructs are heavily teacher-dominated while the latter constructs involve increasingly active learner participation. If teachers consider their students as resisters, receptacles or raw materials, they will force learners to master a language, fill learners with knowledge, and shape learners according to the teacher's wishes. While, if teachers consider their students as clients, partners, individual explorers or democratic explorers, then they will alter the nature of the relationship between teachers and learners. The teachers will have the language learning activities from learners' needs, and take themselves as co-learners, facilitators and co-operators.

“....it is also clear that the extent to which teachers feel able to work with their learners as democratic explorers rather than as, say, clients, often depends on factors outside of their control. In making their beliefs systems about learners explicit, however, teachers should be able to identify inconsistencies and frustrations in their work and thereby search for ways of bridging the inevitable gap between their espoused theories and their theories in action." (Marion Williams et al., 1997)

Effective teacher beliefs about learners are of importance, and are considered as integral components of effective teaching. Melodie Rosenfeld and Sherman Rosenfeld (2008) claimed from their studies that effective teachers act on the belief that all students can learn, meet the needs of diverse learners, and believe that teachers can intervene to make a difference. In other words, effective teachers have interventionist beliefs about students: a set of beliefs that in inclusive classrooms lead to effective teacher practice, and improved student performance and self-esteem. Effective teachers attribute student's learning difficulties to a wider realm, including what the teacher does to help the student. In contrast, less effective beliefs are called pathognomonic. Teachers with pathognomonic beliefs attribute student's learning difficulties to permanent deficits in the student, which detracts from student success.

Nowadays, in China, professionals like Yang Lianrui (1995) analyze teachers' beliefs about learners mainly from two perspectives. From a macrocosmic point of view, they appear to be the teachers' beliefs about the learners' development. 
From a microcosmic point of view, they appear to be the teachers' expectations for the learners. The former beliefs tend to be abstract, but the latter expectations always exhibit concrete qualities, and their impact on the learners' development is much more direct. The teachers' expectations for the learners and their impact arise during the teaching-learning process of interaction between teachers and learners. During this process, teachers constantly insist on influencing the learners according to their own expectations, and the learners will step-by-step develop themselves as the teachers expect.

In the language teaching-learning process, the highly-expected learners will enhance their self-confidence, and develop their language learning abilities completely. The low-expected learners, on the contrary, will feel discouraged and give up working hard, so they can not thoroughly develop their language potential. Therefore, Jere Brophy (1986) advises teachers to "routinely project attitudes, beliefs, expectations, and attributions...that imply that your students share your own enthusiasm for learning. To the extent that 'you treat your students as if they already are eager learners', they will be more likely to become eager learners."

Obviously, having high expectations does not magically equalize students' innate abilities and learning rates. To accommodate differences among students and help all students achieve mastery without resorting to watering down standards and expectations, teachers can manipulate three variables-time, grouping, and methodology (Babara J. Omatoni et al. 1996).

\section{B. Beliefs about Learning}

It is impossible to contemplate teaching in isolation from learning. "Teachers' beliefs about what learning is will affect everything that they do in the classroom, whether these beliefs are implicit or explicit. Even if a teacher acts spontaneously, or from habit without thinking about the action, such actions are nevertheless prompted by a deep-rooted belief that may never have been articulated or made explicit. ...... we can only be really effective teachers if we are clear in our minds what we mean by learning, because only then can we know what kinds of learning outcomes we want our learners to achieve. If our aim is to teach enough language items to pass an exam, then this will have significant implications for the way in which we teach. If, on the other hand, we see learning a new language as a lifelong process with much broader social, cultural and educational implications, then we will take a very different approach to teaching it."(Marion Williams et al., 1997)

British psychologists Gow and Kember (1993) suggest that most approaches to learning can be placed under one of the following headings:

- a quantitative increase in knowledge;

- memorization;

- the acquisition of facts, procedures etc. which can be retained and / or used in practice;

- the abstraction of meaning;

- an interpretative process aimed at the understanding of reality;

- some form of personal change

The first three of these conceptions can be conveniently subsumed under the heading of reproductive approaches, while the subsequent three can be seen as meaning-based. The first three approaches also can be induced as the direct transmission instruction, which implies that teachers' role is to communicate knowledge in a clear and structured way, to explain correct solutions, to give students clear and resolvable problems, and to ensure calm and concentration in the classroom. The following three can be induced as constructivist instruction, which focuses on students not as passive recipients but as active participants in the process of acquiring knowledge, emphasizes facilitating students inquiry, prefers to give students the chance to develop solutions to problems on their own, and allows students to play active role in instructional activities. But these approaches should not be mutually exclusive in language teaching-learning process.

What teaching approaches a teacher uses in the language classroom reflect his/her beliefs about learning. For example, an American teacher educator Diane Holt-Reynolds (1995) from Michigan State University gets the conclusion from her long-term observation that learning occurs inside students' heads as a result of their active efforts to "make meaning" (rather than "getting meaning" through direct transmission). Students' failure to participate and learn in a secondary classroom is often due to instructional problems (especially lack of skills to learn from text) rather than personality or motivational problems, therefore calling for instructional moves by teachers rather than judgments about students' willingness to cooperate.

Teaching well also means learning well to some extent, and teachers' beliefs will subconsciously propel teachers to adopt different teaching-learning methods. When teachers believe that teaching well primarily depends on making school work interesting, they will reject as irrelevant parts of the course that focus on teaching students to use metacognitive strategies for reading to learn. When teachers believe that student's effort is the salient factor contributing to success as a learner, they will reject as irrelevant learning how to foster comprehension skills or how to help students develop study techniques specific to the subject matter they teach. When they believe all students will be like ourselves as able learners, they will find little reason to learn how to analyze the demands inherent to subject-matter texts or how to mediate those demands with inexperienced and unskilled readers. When they believe that teacher-telling like lecturing is a primary vehicle for communicating a teacher's enthusiasm for subject matter, they will react negatively to ideas for cooperative learning. When they see teachers as the primary resource for students' learning, they will reject instructional formats that foster students as independent investigators. 
Constructionists (Marion Williams et al. 1997) hold the idea that "a teacher's deep-rooted beliefs about how languages are learnt will pervade the classroom actions more than a particular methodology s/he is told to adopt or the coursebook s/he follows."

For the language teachers, establishing correct beliefs about learning is to learn that we must be clear about what the language is and how to study language. The viewpoint of communicative teaching is that language is a communicative tool, mainly used to establish and maintain relationships among people. The language learner needs to know about the language rules in various occasions in addition to comprehending language grammar and vocabulary.

There's one western foreign language teaching theory about how to study language: "condition theory". It emphasizes teaching skills and classroom conditions for stimulating learner's psychological process.

First, the learner's language input should be taken into consideration. The American linguist and educationalist Stephen Krashen calls this "I+1 input supposition", because language acquisition will be made only when materials under study contain grammar constructions which are a bit above present level. Second, a favorable, low "emotion filtration" environment in the language class should be formed in order for learners to reach the best emotional state and obtain real language acquisition. Third, learners need not be encouraged to understand every word, they should be taught to comprehend sentence meaning without knowing every word. Do less pattern drills, and more free talk. Offer learners more chances to be exposed to different language models.

American scholar Julianne Turner (2009) thinks that teachers' beliefs about learning appear to rely on a great deal of visible, behavioral evidence rather than on assessment of student meaning-making. Nuthall (2004) argues that for teachers to understand the relation between teaching and learning, they must understand (a) how instruction, management and assessment influence student experience and behavior; (b) how the sociocultural context (classroom instruction, interpersonal relationships, and intrapersonal factors) influence teaching and learning; and (c) how individual students make sense of their classroom experiences.

\section{Beliefs about Themselves}

After having studied teachers' beliefs about learners and learning both in China and abroad, we think some more advanced beliefs about teachers ourselves, such as teacher self-efficacy and teacher emotions can be important ways for us language teachers to enhance our overall quality.

1. Teacher self-efficacy

The well-known psychologist Albert Bandura (1994) defined perceived self-efficacy as people's beliefs about their capabilities to produce designated levels of performance that exercise influence over events that affect their lives. Self-efficacy beliefs determine how people feel, think, motivate themselves and behave. Such beliefs produce these diverse effects through four major processes. They include cognitive, motivational, affective and selection processes.

A strong sense of efficacy enhances human accomplishment and personal well-being in many ways. People with high assurance in their capabilities approach difficult tasks as challenges to be mastered rather than as threats to be avoided. Such an efficacious outlook fosters intrinsic interest and deep engrossment in activities. They set themselves challenging goals and maintain strong commitment to them. They heighten and sustain their efforts in the face of failure. They quickly recover their sense of efficacy after failures or setbacks. They attribute failure to insufficient effort or deficient knowledge and skills which are acquirable. They approach threatening situations with assurance that they can exercise control over them. Such an efficacious outlook produces personal accomplishments, reduces stress and lowers vulnerability to depression.

Tschannen-Moran and Woolfolk Hoy (in press) further defined teacher efficacy as a teacher's "judgment of his or her capabilities to bring about desired outcomes of student engagement and learning, even among those students who may be difficult or unmotivated." So we can say it is a teacher's subjective judgment that s/he could influence the learners' learning process actively.

It has been shown that a high self-efficacy teacher places higher expectations on learners, thinks himself/herself to be responsible for the learners' development, and believes that s/he can teach learners well. S/he constantly explores new teaching methods, and instructs learners more democratically. Since a high self-efficacy teacher can adopt an efficacious teaching behavior, s/he promotes progress among learners. In this sense, a teacher with low self-efficacy will find it difficult to build self-efficacy of others, and difficult to be confident in classroom control. A teacher with low self-efficacy will tend to conduct limited classroom teaching skills and low rates of praise. These teaching behaviors will have classroom be with higher rates of aggression, which in turn can maintain behavior problems. As Woolfolk and Hoy (1990) noted, "Researchers have found few consistent relationships between characteristics of teachers and the behavior or learning of students. Teachers' sense of efficacy ... is an exception to this general rule". That means teachers' self-efficacy determines the teaching behavior.

There is a growing body of evidence that human accomplishments and positive well-being require an optimistic sense of personal efficacy. This is because ordinary social realities are strewn with difficulties. They are full of impediments, adversities, setbacks, frustrations, and inequities (Bandura 1994). So teachers must have a robust sense of self-efficacy to sustain their perseverant efforts needed to succeed in teaching. I like Marie Curie's saying :"Life is not easy for any of us. But what of that? We must have perseverance and above all confidence in ourselves. We must believe that we are gifted for something and that this thing must be attained."

2. Teacher emotions 
Social constructivists Pine and Boy (1977) found that "effective teachers create learning atmospheres which are cognitively and affectively expanding; learning atmospheres which enable the learner to become a more adequate and knowledgeable person." It is clear that this kind of approach places great emphasis upon what the teacher as a person brings to the teaching-learning relationship and how the learner can be helped to develop as a whole person. This is accomplished by providing a supportive learning environment, which allows individuals to develop in their own way. As Pine and Boy (1977) express it, "Pupils feel the personal emotional structure of the teacher long before they feel the impact of the intellectual content offered by that teacher." This obviously has particular implications with regard to a teacher's views of herself or himself. This is equally true when it comes to conveying dignity and respect. Thus, the language teacher needs to convey a sense of self-confidence when using the language, at the same time respecting learners' attempts to express themselves and their views in the language (Marion et al., 1997).

In Paul A. Schutz and Michalinos Zembylas' new book (2009), they claimed that some reports estimate that nearly $50 \%$ of teachers entering the profession leave within the first five years. One explanation of why teachers leave the profession so early in their career might be related to the emotional nature of the teaching profession. For example, teaching is an occupation that involves considerable emotional labor. Emotional labor involves the effort, planning, and control. Teachers need to express organizationally desired emotions during interpersonal transactions. As such, emotional labor has been associated with job dissatisfaction, health symptoms and emotional exhaustion, which are key components of burnout and related to teachers who drop out of the profession. Research into emotional labor in teaching and other aspects of teachers' emotions is becoming increasingly important not only because of the growing number of teachers leaving the profession, but also because unpleasant classroom emotions have considerable implications for student learning, school climate and the quality of education in general.

In Rosemary E. Sutton and Karl F. Wheatley's study (2003), they found that there are empirical and theoretical reasons for believing that teachers' emotions play an important role in teachers, teaching and students. Teachers' emotions may influence not only teachers' cognitions like attention, memory, categorizing, thinking and problem-solving, but also teachers' motivation, attributions, efficacy beliefs and goals. At the same time, although teachers may often attempt to mask their feelings, students are often aware of teachers' emotions, and students are often influenced by teachers' expression of emotions. Teachers' expression of positive emotions, especially caring, are more motivated, less likely to be involved in delinquency, more likely to be helpful, cooperative, and to follow classroom rules and norms. While, teachers' expression of negative emotions mostly make them feel small, sad, ashamed, guilty, hurt and embarrassed.

\section{CONCLUSION}

“Teachers' beliefs are a form of subjective reality: What they believe is real and true." (Heather et al. 2009) Teachers' beliefs influence teacher consciousness, teaching attitude, teaching methods and teaching policy. Teacher beliefs also strongly influence teaching behavior and, finally, learner development. i.e. "their beliefs guide their decision-making, behavior, and interactions with students and, in turn, create an objective reality in the classroom, what students experience as real and true." (Heather et al. 2009) Teachers' beliefs shape their planning and curricular decisions, in effect determining what should be taught and what path instruction should follow.

Teachers who fail to examine their beliefs may bring about unanticipated consequences in the classroom, set aside valuable curriculum, overlook or marginalize students who need them, misinterpret students' motives or behavior, and limit their potential as professionals. Conversely, teachers who are willing to explore their beliefs, and how their beliefs relate to practice and the professional knowledge base, can capitalize on the beliefs they hold to promote students' intellectual growth, autonomy and reciprocity, and equity in their classrooms. Moreover, they create spaces for their own growth as they identify and revise beliefs that do not serve them, their students, or their schools.

The formation of a teacher's educational beliefs in the language teaching-learning process will exert an imperceptible influence on forming active language teaching methods and will bring about an improvement in students' language abilities.

\section{REFERENCES}

[1] Bandura, A. (1994). Self-efficacy. In V. S. Ramachaudran (Ed.), Encyclopedia of human behavior. Vol. 4, pp. 71-81. New York: Academic Press. (Reprinted in H. Friedman [Ed.], Encyclopedia of mental health. San Diego: Academic Press, 1998).

[2] Brophy, Jere. (1986). On Motivating Students. East Lansing, Michigan: Institute for Research on Teaching, Michigan State University, United States. 276-724.

[3] Gow, L. \& D. Kember. (1993). Conceptions of teaching and their relationship to student learning. British Journal of Educational Psychology, 63, 20-33.

[4] Heather Davis \& Carey Andrzejewski. (2009). Teacher Beliefs. The Gale Group. http://www.education.com/reference/article/teacher-beliefs/\#D,.(01-23-2012)

[5] Hoy, W. K., \& Woolfolk, A. E. (1990). Socialization of student teachers. American Educational Research Journal, 27,279-300.

[6] Julianne C. Turner, Andrea Christensen \& Debra K. Meyer. (2009). Teachers' Beliefs about Student Learning and Motivation. Springer International Handbooks of Education, Vol. 21, 5, 361-371.

[7] Kennedy, Mary M. (1997). Defining an ideal teacher education program [mimeo]. Washington, DC: National Council for the Accreditation of Teacher Education. 1-29. 
[8] Korthagen, F. A. J. (2004). In search of the essence of a good teacher: Towards a more holistic approach in teacher education. Teaching and Teacher Education, 20, 77-97.

[9] Linda M. Anderson \& Diane Holt-Reynolds. (1995). Prospective Teachers' Beliefs and Teacher Education Pedagogy [microform]: Research Based on a Teacher Educator's Practical Theory. http://www.eric.ed.gov/contentdelivery/servlet/ERICServlet?accno=ED392792 (02-07-2012)

[10] Meighan, R. \& J. Meighan. (1990). Alternative roles for learners with particular reference to learners as democratic explorers in teacher education courses. The School Field, 1(1), 61-77.

[11] Melodie Rosenfeld \& Sherman Rosenfeld. (2008). Developing effective teacher beliefs about learners: the role of sensitizing teachers to individual learning differences. Educational Psychology, Vol. 28, No. 3, 245-272.

[12] Michael Borg. (2001). Key Concepts in TLT: Teachers' Beliefs. ELT Journal. Vol. 55/2. Oxford University Press.

[13] Nespor, J. (1987). The role of beliefs in the practice of teaching. Journal of Curriculum Studies, 19, 317-28.

[14] Nuthall, G. (2004). Relating classroom teaching to student learning: A critical analysis of why research has failed to bridge the theory-practice gap. Harvard Educational Review, 74, 273-306.

[15] Omotani, Barbara J. \& Les Omotani. (1996). Expect the Best: How Your Teachers Can Help All Children Learn. The Executive Educator. Vol.18, No.8: 519-766.

[16] Pajares M.F. (1992). Teachers' beliefs and educational research: Cleaning Up a Messy Construct. Review of Educational Research. Vol. 62, 3: pp. 307-332.

[17] Schutz \& Michalinos Zembylas. (2009). Introduction to Advances in Teacher Emotion Research: The Impact on Teachers' Lives. Advances in Teacher Emotion Research: The Impact on Teachers' Lives. 3-14. Springer Dordrecht Heidelberg London New York.

[18] Pine, G. J. \& Boy, A. V. (1977). Learner Centered Teaching: A Humanistic View. Denver, Love Publishing Co.

[19] Rosemary E. Sutton \& Karl F. Wheatley. (2003). Teachers' Emotions and Teaching: A Review of the Literature and Directions for Future Research. Educational psychology Review, Vol. 15, No. 4, 327-358.

[20] Tschannen-Moran, M., \& Woolfolk Hoy, A. (2001). Teacher efficacy: Capturing an elusive construct. Teaching and Teacher Education. 17, 783-805.

[21] Williams M. \& Burden R. L. (1997). Psychology for Language Teachers: a Social Constructivist Approach. Cambridge University Press, Cambridge.

[22] Xin Tao \& Shen Juliang. (1999). On Teachers’ Beliefs. Journal of Beijing Normal University. Vol. 1. 5-12.

[23] Yang Lianrui. (1995). English Pedagogy. Shan Dong: Shan Dong University Press.

[24] Zhou Guotao \& Liu Xiaoming. (1997). Monograph of Educational Psychology. Beijing: China Audit Press.

Li Xu was born in Yingkou, Liaoning Province, China in 1968. She received her M.Ed. degree in English education \& curriculum from the School of Foreign Languages, Northeast Normal University, China in 2000.

She is a lecturer in the School of Foreign Languages, Dalian University of Technology, Dalian, China. Her main research interests lie in applied linguistics, like CALL, TESOL and ESP. 